Article

\title{
Implementing Green Infrastructures beyond Protected Areas
}

\author{
Sabrina Lai ${ }^{1}$, Federica Leone ${ }^{2, *}$ and Corrado Zoppi ${ }^{2}$ (I) \\ 1 Regional Administration of Sardinia, Department for the Environment, via Roma 80, 09123 Cagliari, Italy; \\ slai@regione.sardegna.it \\ 2 Department of Civil and Environmental Engineering and Architecture, University of Cagliari, \\ Via Marengo 2, 09123 Cagliari, Italy; zoppi@unica.it \\ * Correspondence: federicaleone@unica.it; Tel.: +39-070-6755213
}

Received: 7 August 2018; Accepted: 30 September 2018; Published: 2 October 2018

check for updates

\begin{abstract}
According to the European Commission, green infrastructure (GI) is conceived as a strategically planned network of natural and semi-natural areas. This definition highlights three important issues: environment protection, ecosystems multifunctionality and ecological connectivity. Building upon a methodology that identifies a Sardinian regional GI in relation to four values (conservation value, natural value, recreational value and landscape value), this study aims at assessing the suitability of areas situated within and outside protected areas' boundaries to be included in the above-mentioned Sardinian regional GI. In relation to conservation value, outcomes reveal a higher suitability of patches situated within protected areas to be included in the regional GI, whereas in relation to the other three values, the behavioral patterns are less evident. These results suggest specific policy recommendations such as mitigation of land-taking processes, increase of Natura 2000 Network's size, accurate identification of landscape goods, and improved accessibility to sites characterized by outstanding natural beauty.
\end{abstract}

Keywords: green infrastructure; ecosystem services; Natura 2000 Network; environmental planning

\section{Introduction}

An important definition of green infrastructure (GI) is proposed by the European Commission in its Communication titled "Green infrastructure: enhancing Europe's natural capital", where GI is regarded as a network having the Natura 2000 sites at its core, capable of delivering numerous ecosystem services (ES), and is "strategically planned", emphasizing the role of GI with regards to the integration of ecological connectivity and protection of the environment, and ecosystems' multiple functions, drawing on Benedict and McMahon [1] (p. 1), according to whom GI is "an interconnected network of natural areas and other open spaces that (...) provides a wide array of benefits for people and wildlife". As a consequence, identifying and managing GI is a core planning issue [2] especially under the provisions of the European Landscape Convention [3].

As for connectivity, Lennon [4] highlights that, notwithstanding differences in defining GI, common conceptualizations of GI relate to networks, hence stressing that rather than protecting individual, isolated parcels of natural or seminatural areas, planning should take care of interconnected networks [5], comprising both core areas that support key ES and corridors that support species movements and dispersal (respectively, "hubs" and "links" in Lafortezza et al. [6]).

With reference to multifunctionality, this is commonly understood as the combination of "ecological, social and economic, abiotic, biotic and cultural function of green spaces" [7] or "the ability to provide several functions and benefits on the same spatial scale" [8]. As a consequence, GI multifunctionality has been analyzed in the light of the ES framework [7]; where ES are those goods 
and services supplied by nature that sustain life and contribute, both directly and indirectly, to human wellbeing, variously defined, and classified in the literature according to many different frameworks (prominently, the Millennium Ecosystem Assessment [9]; in Europe, the Common International Classification for Ecosystem Services (CICES) by the European Environment Agency [10]; and, in the US, the Final Ecosystem Goods and Services Classification System (FEGS-CS) by the United States Environmental Protection Agency [11]).

Beneficial functions provided by GI are broadly categorized by Pauleit et al. (as cited in Hansen and Pauleit [7]) into ecological, social and economic categories, while Taylor-Lovell and Taylor [12] explicitly group those ES and functions that, in their view, should be supplied by GI: production (including provisioning ecosystem services such as food or timber production), ecological (including supporting and regulatory ecosystem services, such as water purification or climate regulation), and cultural (including recreation, landscape quality, cultural heritage); the need to take into account communities' and users' needs and preferences is also underlined. This study emphasizes the second characteristic of GI, that is, the multifunctional use of natural capital that allows for multiple purposes, while connectivity can be easily integrated using the same methodology as in Cannas et al. [13].

According to Hansen and DeFries [14], protected areas are planned so as to implement virtuous ecological and socio-economic interactive relationships with surrounding areas, and, by doing so, build an integrated ecosystem. Furthermore, the assessment of protected area-related spatial policies could represent a reference point to enhance the efficiency and effectiveness of policy measures aimed at implementing environmental protection and related management measures $[15,16]$.

Identifying and planning regional GI can be considered as an intentional way of spreading the positive impacts of environmental conservation policies across a spatial context much more complex and larger than the protected areas. Urban and rural settlements can be part of the spatial context of the regional GI as well $[17,18]$.

This study builds upon a methodology applied in previous studies by Arcidiacono et al. [19] and by Lai and Leone [20], which both map a regional GI taking an Italian region as a case study. In the former, a GI for Lombardy was identified as a multifunctional GI taking into account three values: natural value, recreation value, and landscape value. In the latter, a Sardinian GI was identified based upon four factors, i.e., adding to the three values used in Arcidiacono et al. [19] a fourth layer accounting for conservation value.

Conservation value (VAL_C) is based on the presence of areas whose natural characteristics are particularly important because hosting habitats rare, endangered, or representative of European biogeographical regions (i.e., habitats of community interest under the provisions of the Habitats Directive (no. 93/43/EEC)). Such habitats are meant to be maintained or restored in a favorable conservation status, and their presence calls for the designation of Natura 2000 sites, when criteria listed in Annex III of the Habitats Directive (concerning representativity, size, conservation status, and significance of the site) are met. According to a recent study [21] carried out to explore Finnish experts' perceptions on GI implementation, the importance of GI in relation to biodiversity conservation has been emphasized by the majority of respondents. Moreover, GI can contribute to the reduction of habitat fragmentation which is one of the primary causes of species extinction [22].

Natural value (VAL_N) is related to biodiversity's capacity of providing ES; hence, it implies ecological integrity and current levels of ecosystem functions, key to supplying human-demanded ES. As such, under the Millennium Ecosystem Assessment [9] classification it would be categorized under the supporting services group. In the literature, trade-offs between ES are often analyzed and assessed through land use/land cover changes [23-25]. For example, Yang et al. [25] studied the impacts of land use changes on ES trade-offs in the case of Yahne watershed in the Loess Plateau, China. In particular, their study investigates land use patterns that mitigate conflicts between food supply and conservation measures in order to be included within future restoration policies.

Recreation value (VAL_R) concerns the landscape attractiveness for recreational activities. Landscapes and natural habitats are accounted for when choosing holiday locations or doing outdoor 
activities (prominently, active tourism), thus they positively affect both local communities' and tourists' quality of life and wellbeing, while also benefitting local economies. Therefore, recreation value accounts for cultural ES, as classified by the Millennium Ecosystem Assessment [9]. In the literature, recreation value is assessed through monetary analyses [26-29] or through non-monetary analyses [30-32]. In the last decades, non-monetary methods based on social media approaches have been used to assess recreation value [33-35]. For instance, Cunha et al. [36] evaluated recreation services combining social media-based methods (using the InVEST recreation model) and official data sources in the Northwest coast of Portugal.

Finally, Landscape value (VAL_L) accounts for the interactions between natural and human factors that have shaped European cultures, as per the European Landscape Convention, and it is here assessed based on the endowment of natural and cultural resources, which are identified as landscape-related goods by the Italian Code on cultural goods and landscape (Law enacted by decree no. 2004/42). Various authors have highlighted the importance of landscape value within spatial planning $[37,38]$ and also in relation to the definition of GI [19].

Once a regional GI is identified, the eligibility of areas located inside and outside protected areas (national and regional parks, sites protected under the provisions of the Ramsar Convention and sites belonging to the Natura 2000 Network, identified with reference to the Habitats Directive and to the Birds Directive (no. 2009/147/EC)) are assessed on the basis of the four factors indicated above.

The discussion on the relationship between the regional GI and protected areas provides important insights concerning the definition and implementation of spatial planning policies aimed at increasing the ecosystems' capacity of providing services by spreading environmental protection beyond the boundaries of protected areas, and by proposing a holistic planning approach based on the implementation of the regional GI.

The study is structured as follows. The next section describes the methodological approach and the regional context for its implementation. The third section shows the results concerning the spatial taxonomy of the eligibility of areal units to be part of the Sardinian regional GI, on the basis of the four factors indicated above. In the final section, the outcomes and proposed directions for future research are discussed.

\section{Materials and Methods}

The Sardinian region, an Italian island of approximately $24,000 \mathrm{~km}^{2}$ in size, is here taken as a case study. Protected areas (which include national parks, regional parks, Natura 2000 sites, and wetlands of international importance, hereinafter "Ramsar sites") concern around 19\% of the island's land mass. Since 2006, a Regional Landscape Plan (RLP) is in force; such plan does not contain any provisions for a regional GI.

As Figure 1 shows, two national parks, four regional parks, five marine protected areas, 125 Natura 2000 sites and eight Ramsar sites are included in the study area.

As stated in the introduction, VAL_C accounts for the presence of natural habitats regarded as worth preserving in a favorable conservation status by the European Commission. VAL_C is here computed following the methodology provided in a regional report [39], where habitats of community interest are classed and prioritized with a view to defining a regional monitoring plan. VAL_C is assessed only in those areas where habitats of community interest have been identified, as:

$$
\text { VAL_C }=\mathrm{P} \times(\mathrm{R}+\mathrm{T}+\mathrm{K}),
$$

where:

- P stands for priority; it accounts for the presence and significance, in a given land parcel, of habitats of community interest as listed in Annex I of the Habitats Directive, and can only take three values: $\mathrm{P}=0$ if no habitats of community interest are present (which also entails that in such cases VAL_C $=0$ ); $\mathrm{P}=1.5$ in case of a priority habitat (these are defined as natural habitat 
types in danger of disappearance, calling for an early implementation of conservation measures, and marked with an asterisk in Annex I of the Habitats Directive); P = 1 otherwise;

- R stands for rarity and, for each habitat, it is quantified based on the habitat's occurrences within the Sardinian Natura 2000 standard data forms, normalized in the (1-5) interval. The fewer the occurrences, the higher $\mathrm{R}$ is;

- $\quad \mathrm{T}$ stands for threats and is quantified based on the number of threats listed in the regional Natura 2000 standard data forms, normalized in the (1-5) interval. The more the threats for a given site, the higher T;

- K stands for knowledge, which was assessed, for each habitat, by experts in the field of natural conservation within a regional monitoring program [40] by using qualitative judgments (good, acceptable, sufficient, poor). In this study, the qualitative score was next turned into a quantitative one, within the (1-4) interval. The maximum achievable score is lower than those of both $\mathrm{R}$ and $\mathrm{T}$ to take into account the subjectivity embedded in the experts' judgments. Incorporating expert knowledge in assessing ecosystem values and services is a common approach that can be found, for instance, in Burkhard et al. [41,42], or in de Groot et al. [43]. The lower the level of knowledge on a given habitat, the higher $\mathrm{K}$ is, because, in line with the precautionary principle, low knowledge on a certain habitat's spatial distribution and conservation status calls for greater attention and stricter conservation measures.

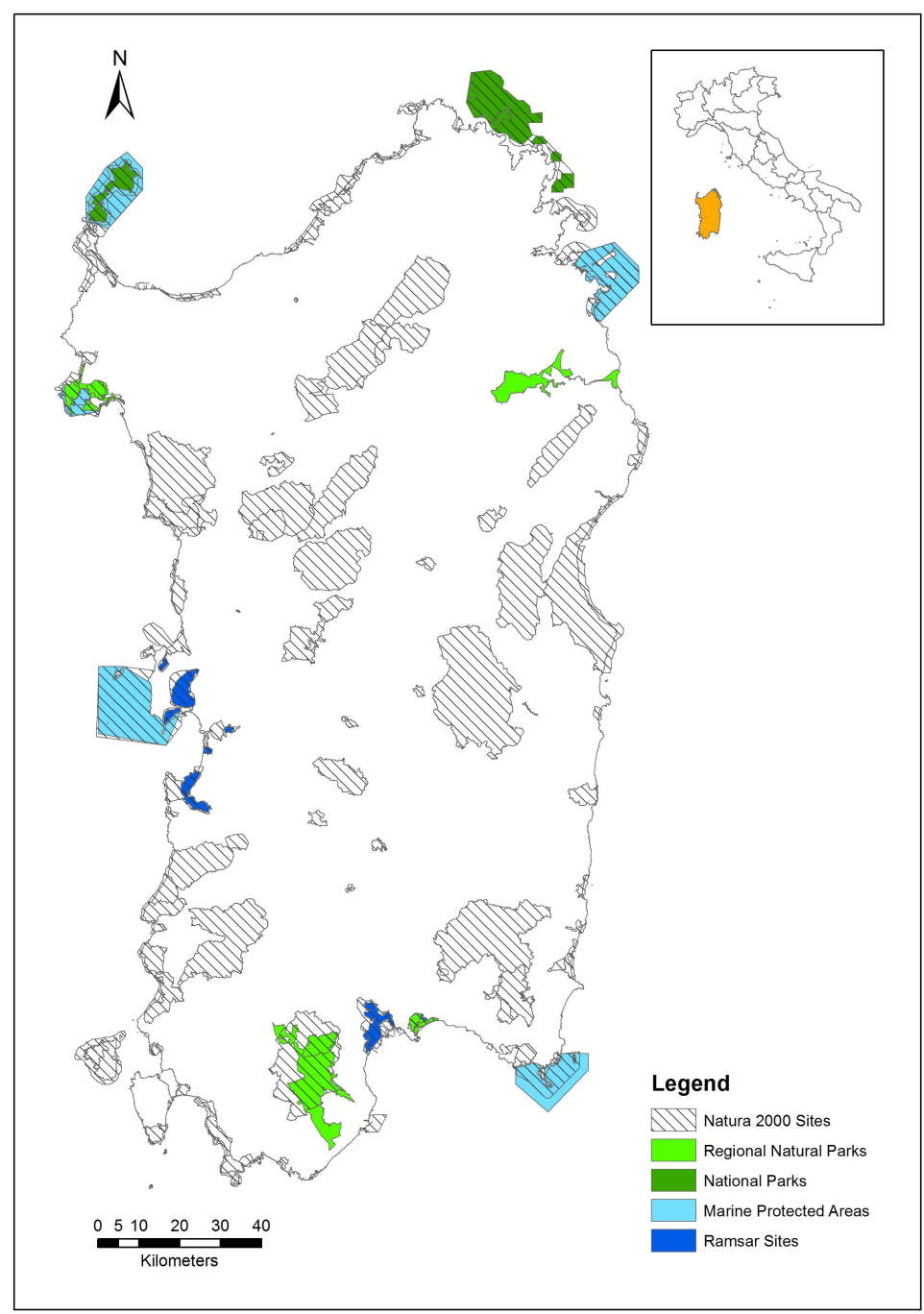

Figure 1. Study area. 
As for the spatial identification of the regional GI, the methodology developed by Lai and Leone [20] is applied here. Hence, four factors (VAL_C, VAL_N, VAL_R, VAL_L) representing the landscape's multifunctional character are calculated and mapped using GIS.

As a result, VAL_C can range between 0 (where no habitats of community interest are present) and 21. The values were next normalized in the (0-1) interval.

VAL_N is assessed and mapped using the "Habitat quality" model of the "InVEST" software program and ranges between 0 and 1 . Input data used to feed the model are provided in Table 1.

VAL_R was assessed and mapped using the InVEST model "Visitation: recreation and tourism", which harvests data from the social media Flickr, whose users can upload georeferenced pictures. The area of interest is fed into the model, which next calculates the "photo-user-day" (PUD), i.e., the total number of pictures uploaded by each single user in a certain cell (whose size is set by the modeler) and in a single day. PUD was assessed within cells of 500*500 meters and considering pictures uploaded between 2010 and 2014. VAL_R equals PUD normalized in the (0-1) interval.

VAL_L refers to landscape assets as listed in, and protected by, the RLP. For each type of asset, a score ranging from 0 to 1 was assigned by experts. The higher the score, the stricter the rules provided within the plan to preserve that specific type of asset, and hence the higher the landscape value implied within the plan. In the event of overlapping landscape assets, the score corresponding to the strictest protection level in that area was assigned.

Table 1. Input data used for the Habitat quality model, data used and authors' elaborations.

\begin{tabular}{|c|c|}
\hline Required Input & Data Used \\
\hline Land use/land cover map & $\begin{array}{l}\text { Regional vector land cover map produced by the Regional } \\
\text { Administration of Sardinia in 2008, third level of the CORINE } \\
\text { nomenclature, rasterized. }\end{array}$ \\
\hline Threats to habitats & $\begin{array}{l}\text { A list of threats to biodiversity, identified on the basis of Natura } 2000 \\
\text { standard data forms pertaining to Sardinian Natura } 2000 \text { sites. To each } \\
\text { threat, a weight and a distance decay were assigned based on the } \\
\text { outcomes of a survey involving five selected experts in the field of } \\
\text { biodiversity and environmental assessments. }\end{array}$ \\
\hline Impact sources & $\begin{array}{l}\text { A raster map showing the spatial distribution of each of the } 10 \\
\text { above-mentioned threats. }\end{array}$ \\
\hline Accessibility to sources of degradation & $\begin{array}{l}\text { A vector map describing accessibility to sources of degradation, under } \\
\text { the assumption that the stricter the legal/institutional protection, the } \\
\text { lower the accessibility. On this basis, the following three protection } \\
\text { levels were mapped: regional and natural parks, together with public } \\
\text { woods managed by the Regional Forestry Agency (highest protection } \\
\text { level: accessibility set to } 0.2 \text { ); Natura } 2000 \text { sites (intermediate level: } \\
\text { accessibility set to 0.5); and the remaining part of the island (lowest } \\
\text { level: accessibility set to } 1 \text { ). }\end{array}$ \\
\hline $\begin{array}{l}\text { Habitat types and sensitivity of each habitat } \\
\text { to each threat }\end{array}$ & $\begin{array}{l}\text { A matrix listing land cover types (third level of the CORINE taxonomy) } \\
\text { in the first column; for each land cover, a (0-1) score of its suitability to } \\
\text { be regarded as habitat (second column), and a (0-1) score of its } \\
\text { sensitivity to each of the } 10 \text { above-mentioned threats ( } 3 \text { rd to } 12 \text { th } \\
\text { column) is given; sensitivity levels were assigned through an } \\
\text { expert-based approach. }\end{array}$ \\
\hline Half-saturation constant & Default value (i.e., 0.5). \\
\hline
\end{tabular}

VAL_C,VAL_N, VAL_R, and VAL_L, all taking values between 0 and 1, were mapped and summed using GIS techniques, which returned a map showing the total value (VAL_T), ranging from 0 to 4.

This study aims to assess whether and how each of the four values affects the suitability of areas (within or outside protected areas) to be part of a regional GI. To this end, two macro-categories were differentiated: a) natural protected areas (including national parks, regional parks, Natura 2000 sites, Ramsar sites); b) the rest of the island (unprotected areas). Among natural protected areas, marine protected areas were not included because the analysis only concerns terrestrial areas. VAL_T 
occurrences were arranged into tertiles. For both macro-categories (i.e., natural protected areas and unprotected areas), for each VAL_T tertile and for each of the four values (i.e., VAL_C, VAL_N, VAL_R, and VAL_L), parcels showing null values were observed and the percentage of their area with respect to the total area of the macro-category in the tertile was calculated. For both macro-categories and for each tertile, the means, medians and standard deviations of each of the four values were also taken into account.

This study focuses on the definition of spatial planning policies aiming at enhancing the environmental quality of the Sardinian region by increasing the size of the regional GI. These policies concern areas that are not eligible to be part of the regional GI, that is, the patches taking null values in terms of VAL_T. These areas are targeted for improvement in their present status of non-eligibility in order to increase the size of the regional GI, and, by doing so, the dissemination of its beneficial effects. Results, discussion and conclusions compare the outcomes related to VAL_T and its four determinants with regards to protected and unprotected areas, and identify policy recommendations taking account of the findings coming from this comparative assessment, based on the analysis of the spatial taxonomy of null values of VAL_T.

\section{Results}

The outcomes of the analysis are provided in Figures 2 and 3, and Table 2.

Figure 2 shows, arranged into tertiles and for the whole island, the spatial layout of the total value (VAL_T, left-hand side frame).
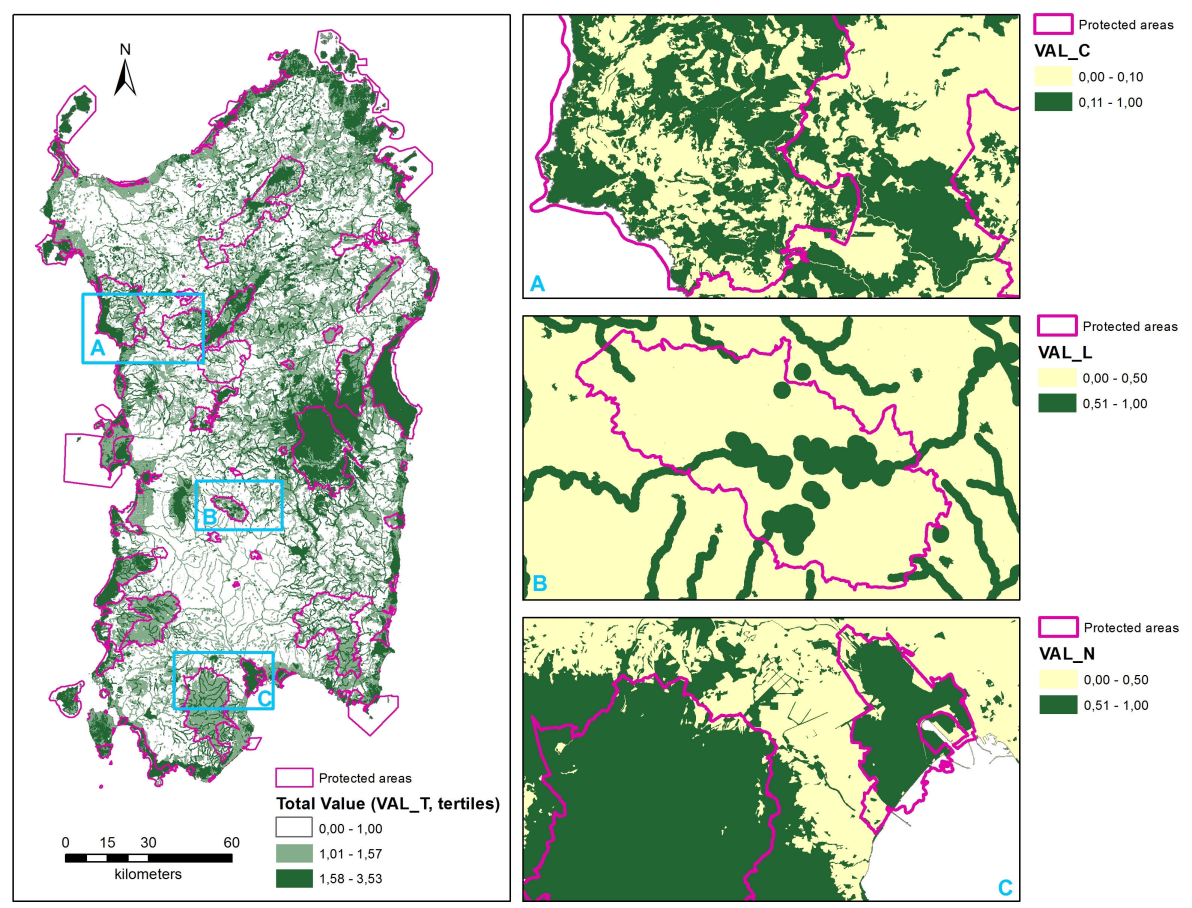

Figure 2. Spatial distribution of the total value (VAL_T), classed into three tertiles (left); some local examples concerning VAL_C (a), VAL_L (b), and VAL_N (c) (right).

The three smaller frames on the right-hand side provide, at the local scale, some examples concerning (top to bottom) VAL_C, VAL_L, and VAL_N. As for VAL_C, the detailed map makes it evident that in the surroundings of Bosa (a historic town in north-west Sardinia, a quite renowned tourist destination), large patches of habitats of community interest are located between two protected areas (namely, SAC ITB020041 "Entroterra e zona costiera tra Bosa, Capo Marargiu e Porto Tangone" and SAC ITB020040 "Valle del Temo" to the left, and SPA ITB023050 "Piana di Semestene, Bonorva, Macomer e Bortigali") outside their boundaries. Thus, such habitats currently do not enjoy any 
protection under the Habitats Directive. With regard to VAL_L, the detailed map shows that inside the SCI ITB041112 "Giara di Gesturi", a basaltic plateau in the inner part of the island, known for its temporary ponds, cork trees, and wild horses, some small patches of land taking high values of VAL_L can be found. These mainly refer to "nuraghi", prehistoric megalithic buildings that date back from the second millennium B.C. to the Iron Age [44] and that are a distinctive feature of Sardinian prehistoric culture. Only some rough estimates of the total number of nuraghi in the whole of Sardinia are available, ranging from around 7000 [45] to more than 7000 [46] to more than 8000 [47], with many either incorrectly located or not unearthed yet. Finally, the third frame concerns the area between the SCI ITB041105 "Foresta di Monte Arcosu" (partly included in a regional park) to the left and the SAC ITB040023 "Stagno di Cagliari, Saline di Macchiareddu, Laguna di Santa Gilla" (partly designated also as SPA), in the outskirts of the island's capital city, Cagliari, to the right. As the detailed map shows, while inside the two protected areas, VAL_N takes very high values, between the two protected areas low values can be found. This is mainly due to three reasons: first, the land cover, when not artificial, is seminatural as opposed to natural; second, the high accessibility due to the presence of main road infrastructure; and third, the presence of a large industrial site, including an incinerator, a windfarm, a saltpan, and what remains of industrial buildings and activities installed in the second half of the 20th century.

In Figure 3, the spatial layout of the four values (VAL_C, VAL_N, VAL_R, and VAL_L) is provided; for each value, null and non-null occurrences are differentiated. Furthermore, in each frame, the protected areas' boundaries are also shown, so as to qualitatively appreciate differences in each value's occurrences within and outside protected areas. For instance, VAL_N's null occurrences can generally be found outside protected areas; this also applies to VAL_C, but, contrary to the previous case, null occurrences largely prevail over non-null ones.

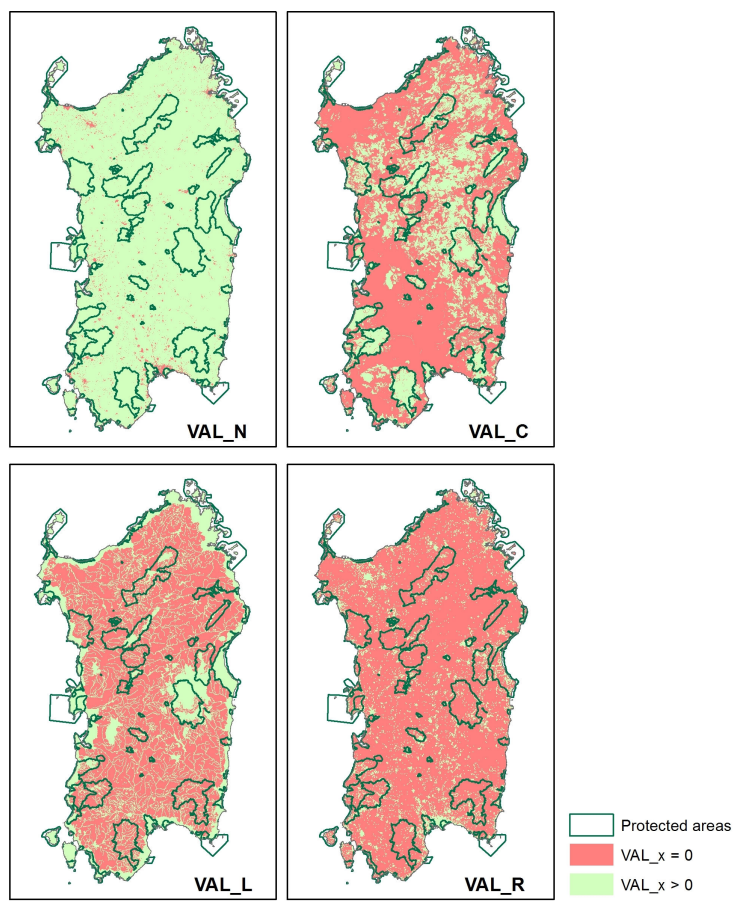

Figure 3. Spatial distribution of VAL_N, VAL_C, VAL_L and VAL_R showing patches having null and non-null values.

Table 2 shows the quantitative results of the analysis, grouped into the two macro-categories of natural protected areas and unprotected areas (first column); for each, the results are further grouped according to VAL_T tertiles (second column). Next, let us denote VAL_x as any of the four values (i.e., VAL_C, VAL_N, VAL_R, or VAL_L): in the third column, for each macro-category and for each 
tertile, some descriptive indicators are provided: VAL_x's mean value, median and standard deviation; number of patches taking the null value of VAL_x together with the percentage of patches with reference to the total number of patches belonging to the corresponding macro-category and tertile; total area of patches taking the null value of VAL_x together with the percentage of the area taking the null value of VAL_x with reference to the total area included within the corresponding macro-category and tertile.

Table 2. Mean value, median, standard deviation, number and total area of patches with null value, percentage of the number and of the total area of patches with null value in relation to, respectively, the total number and total area of patches in the reference tertile, for both natural protected areas and unprotected areas and for each of the four values.

\begin{tabular}{|c|c|c|c|c|c|}
\hline & & VAL_C & VAL_N & VAL_R & VAL_L \\
\hline \multicolumn{6}{|c|}{ Natural protected areas $(467,635.13 \mathrm{ha})$} \\
\hline & mean & 0.13 & 0.55 & 0.002 & 0.11 \\
\hline & median & 0.00 & 0.50 & 0.00 & 0.00 \\
\hline 1st tertile: & standard deviation & 0.17 & 0.33 & 0.01 & 0.31 \\
\hline VAL_T $=[0-1]$ & no. patches VAL_x $=0$ & 17,366 & 4526 & 23,944 & 24,401 \\
\hline \multirow[t]{5}{*}{$(94,150.93 \mathrm{ha})$} & $\%$ patches VAL_x $=0^{1}$ & 63.34 & 16.51 & 87.34 & 89.01 \\
\hline & total area VAL_x $=0$ [ha] & $87,332.79$ & 2063.00 & $89,766.74$ & $93,097.17$ \\
\hline & $\%$ area VAL_x $=0^{2}$ & 92.76 & 2.19 & 95.34 & 98.88 \\
\hline & mean & 0.25 & 0.47 & 0.017 & 0.57 \\
\hline & median & 0.29 & 0.50 & 0.01 & 1.00 \\
\hline 2nd tertile: & standard deviation & 0.21 & 0.44 & 0.04 & 0.49 \\
\hline VAL_T $=[1-1.57]$ & no. patches VAL_x $=0$ & 16,661 & 20,482 & 24,064 & 20,825 \\
\hline \multirow{5}{*}{$(148,548.90 \mathrm{ha})$} & $\%$ patches VAL_x $=0^{1}$ & 33.99 & 41.78 & 49.09 & 42.48 \\
\hline & total area VAL_x $=0$ [ha] & $30,961.17$ & 3244.88 & $123,262.52$ & $120,388.14$ \\
\hline & $\%$ area VAL_x $=0^{2}$ & 20.84 & 2.18 & 82.98 & 81.04 \\
\hline & mean & 0.34 & 0.89 & 0.024 & 0.95 \\
\hline & median & 0.36 & 1.00 & 0.00 & 1.00 \\
\hline 3rd tertile: & standard deviation & 0.24 & 0.23 & 0.07 & 0.18 \\
\hline VAL_T $=[1.57-3.53]$ & no. patches VAL_x $=0$ & 21,452 & 2102 & 44,796 & 2741 \\
\hline \multirow[t]{3}{*}{$(224,935.30 \mathrm{ha})$} & $\%$ patches VAL_x $=0^{1}$ & 24.41 & 2.39 & 50.98 & 3.12 \\
\hline & total area VAL_x $=0$ [ha] & $45,805.20$ & 509.24 & $160,293.70$ & 9970.11 \\
\hline & $\%$ area VAL_x $=0^{2}$ & 20.36 & 0.23 & 71.26 & 4.43 \\
\hline \multicolumn{6}{|c|}{ Unprotected areas $(1,940,665.60 \mathrm{ha})$} \\
\hline \multirow{7}{*}{$\begin{array}{c}\text { 1st tertile: } \\
\text { VAL_T }=[0-1] \\
(1,015,579.00 \mathrm{ha})\end{array}$} & mean & 0.08 & 0.53 & 0.005 & 0.05 \\
\hline & median & 0.00 & 0.50 & 0.00 & 0.00 \\
\hline & standard deviation & 0.15 & 0.29 & 0.02 & 0.21 \\
\hline & no. patches VAL_x $=0$ & 132,144 & 22,824 & 129,865 & 157,793 \\
\hline & $\%$ patches VAL_x $=0^{1}$ & 79.62 & 13.75 & 78.25 & 95.08 \\
\hline & total area VAL_x $=0$ [ha] & $963,608.81$ & $50,825.56$ & $940,178.56$ & $999,186.97$ \\
\hline & $\%$ area VAL_x $=0^{2}$ & 94.88 & 5.00 & 92.58 & 98.39 \\
\hline \multirow{7}{*}{$\begin{array}{c}\text { 2nd tertile: } \\
\text { VAL_T = [1-1.57] } \\
(563,063.30 \mathrm{ha})\end{array}$} & mean & 0.15 & 0.60 & 0.012 & 0.61 \\
\hline & median & 0.00 & 0.50 & 0.00 & 1.00 \\
\hline & standard deviation & 0.21 & 0.33 & 0.04 & 0.48 \\
\hline & no. patches VAL_x $=0$ & 73,136 & 15,193 & 67,584 & 43,224 \\
\hline & $\%$ patches VAL_x $=0^{1}$ & 64.27 & 13.35 & 59.39 & 37.98 \\
\hline & total area VAL_x $=0$ [ha] & $271,474.10$ & $21,355.85$ & $448,720.03$ & $328,386.09$ \\
\hline & $\%$ area VAL_x $=0^{2}$ & 48.21 & 3.79 & 79.69 & 58.32 \\
\hline \multirow{7}{*}{$\begin{array}{c}\text { 3rd tertile: } \\
\text { VAL_T }=[1.57-3.53] \\
(362,023.30 \mathrm{ha})\end{array}$} & mean & 0.24 & 0.86 & 0.019 & 0.96 \\
\hline & median & 0.29 & 1.00 & 0.00 & 1.00 \\
\hline & standard deviation & 0.23 & 0.23 & 0.08 & 0.16 \\
\hline & no. patches VAL_x $=0$ & 40,890 & 868 & 64,398 & 2338 \\
\hline & $\%$ patches VAL_x $=0^{1}$ & 43.43 & 0.92 & 68.41 & 2.48 \\
\hline & total area VAL_x $=0$ [ha] & $198,254.15$ & 1134.46 & $305,528.38$ & $17,732.95$ \\
\hline & $\%$ area VAL_x $=0^{2}$ & 54.76 & 0.31 & 84.39 & 4.90 \\
\hline
\end{tabular}

${ }^{1}$ percentage of patches with VAL_x $=0$ with respect to the total number of patches in the corresponding tertile.

2 percentage of areas with VAL_x $=0$ with respect to total area included in the corresponding tertile. VAL_ $x=$ (VAL_C, VAL_N, VAL_R, VAL_L). 


\subsection{Natural Protected Areas}

Within natural protected areas, the means of the four values steadily increase from the first to the second and third tertiles, the only exception being VAL_N's mean, which decreases from 0.55 to 0.47 between the first and the second tertile and then increases up to 0.89 . As for the patches taking null values, in the first and second tertiles, the highest percentages correspond to VAL_L and VAL_R, while, in the third tertile, the highest percentages correspond to VAL_C and VAL_R.

With reference to VAL_N, these outcomes are likely to be related to the land cover quality (since the more degraded the land covers, the lower the value of VAL_N), and to threats to habitats that negatively affect their quality and, therefore, result in lower VAL_N figures.

The behavior of VAL_C is related to the presence of habitats of community interest, which are found and monitored mostly inside Natura 2000 sites.

Concerning VAL_L, which is linked to the presence of landscape assets, the area of the null value patches belonging to the third tertile is very low and the area of the non-null value patches is high. The area of the non-null patches within the second tertile goes down and it is close to zero in patches belonging to the first tertile.

Finally, as for VAL_R, which is dependent (among others) on the attractiveness of the visual landscape and on the accessibility of the patches, the share of the area of the null-value patches is higher than $70 \%$ irrespective of the tertile.

The low presence of patches taking null values of VAL_N can be observed by looking at the number and percentage of patches, and becomes even more evident by observing the percentage of area (respectively, in the three tertiles: $2.19 \% ; 2.18 \% ; 0.23 \%$ ). Moreover, and still looking at the percentage of area taking null values, the highest values pertain to VAL_R (respectively, in the three tertiles: $95.34 \% ; 82.98 \% ; 71.26 \%$ ), although the maximum value corresponds to VAL_L $(98.88 \%$ in the first tertile), while, as for VAL_C, a very high value can be observed in the first tertile and moderate values in the second and third.

\subsection{Unprotected Areas}

Unprotected areas always show increasing values of the mean for each VAL_x when switching from the first to the second and third tertiles. To the contrary, the percentage of patches taking null values steadily decreases for any VAL_x when switching from the first to the second and third tertiles; moreover, VAL_N always shows the lowest values (respectively, in the three tertiles: $13.75 \%$; $13.35 \%$; 0.92\%), while VAL_C and VAL_R show the highest values (always between $40 \%$ and $80 \%$ ). VAL_L shows the most significant variations, since it equals $95.08 \%$ in the first tertile and $2.48 \%$ in the third. As for the percentage of areas taking null values, the trend is very similar to that described for the percentage of patches taking null values, although, for each VAL_x, observed values are quite different.

As with protected areas, low VAL_N values might possibly depend on land cover quality and threats to biodiversity, among which urbanization and the presence of infrastructure are particularly prominent.

The behavior of VAL_C within unprotected areas is quite different to that inside protected areas: the values are lower, since the presence of habitats of community interest calls for the designation of Natura 2000 sites, when criteria listed in the Habitats Directive are met.

To the contrary, VAL_L is generally higher in unprotected areas than in protected areas, and hence the number of landscape assets located in the former should be comparatively higher than in the latter.

Similarly to protected areas, concerning VAL_R, the share of the area of the null-value patches is quite high irrespective of the tertile. Since accessibility is a key factor that affects VAL_R, the higher share of null-value patches in unprotected areas than in natural protected areas can be attributed to the different environmental protection regimes in force, which influence accessibility. 


\section{Discussion}

In Section 2 above it is highlighted that this study aims at identifying spatial planning policies to improve environmental quality in Sardinia by increasing the size of the regional GI. Such policies primarily target patches taking null values in terms of VAL_T, therefore, from the multifunctionality standpoint, this refers to areas that do not perform any of the functions implied by the four values. As a consequence, planning recommendations provided in the following paragraphs ultimately aim at achieving multifunctionality.

The outcomes of this study show evidence that VAL_N takes rather high average values, both in the case of protected and unprotected areas, with reference to the third tertile of the total value. Moreover, VAL_N takes comparatively lower average values with regards to the first and the second tertiles ( 0.55 and 0.47 respectively in case of protected areas, and 0.53 and 0.60 in the other case). In all three tertiles, the sum of the areas of patches showing null values for VAL_N is relatively small, both in the case of protected and unprotected areas, since it never exceeds $5 \%$.

That being said, in terms of spatial policies aimed at strengthening the eligibility of areal units to be part of the Sardinian regional GI, the taxonomy of VAL_N suggests that two types of plan actions should be taken into account as particularly effective, both in the case of protected and unprotected areas. The most important of these is related to patches showing non-null values, especially in case they belong to the first or second tertiles of the total value distribution. In these tertiles, the mean and median values of these patches are in the range $0.4-0.6$, and they are quite similar to each other in the case of protected and unprotected areas; standard deviations are also quite similar. As a consequence, they entail plenty of room for improvement. Indeed, two variables should be targeted in effective spatial policies: 1) the reduction of threats, which, for instance, can be implemented through the renaturation of soils sealed as a consequence of urbanization, the removal of illegal (and legal) waste disposal sites, the regeneration of undergrowth, monitoring pasture and grazing land condition, and moving industrial facilities which generate dangerous environmental impacts (as, for instance, in the Cagliari case mentioned in Section 3, and mapped in Figure 2C); and 2) the mitigation of land-taking processes and of land cover transitions characterized by qualitative degradation [48,49]; indeed, it must be taken into account that the most outstanding issue which influences VAL_N is the quality of land cover. These results are supported by other studies [50,51]. For example, He et al. [50] propose a tool to forecast the impact of land cover changes on habitat quality through a methodology that combines cellular automata scenario simulation and InVEST's Habitat quality model. Their results suggest two policies to improve habitat quality: 1) reducing urban sprawl through a rational and balanced urban increase rate, and, 2) balanced agricultural policies to eliminate scattered rural residential villages that generate a decrease in habitat quality in their surrounding areas. Sallustio et al. [51] define a methodology to support decision makers in identifying areas for conservation strategies and assessing habitat quality and degradation in relation to the current pattern of Italian protected areas. Their results suggest that habitat quality decreases as the distance to more densely populated areas decreases; in addition, it decreases in proximity to areas characterized by more intensive agricultural uses and in relation to more loosened conservation measures that characterize different categories of protected areas.

The implications concerning VAL_C are quite different. The mean and median values of patches of protected areas concerning the three tertiles are significantly higher than the corresponding values of unprotected areas (except for the median value in the first tertile, which equals 0 in both cases); this comparison is made robust by the similar values concerning the dispersion of the distribution, as highlighted by the standard deviations. Values are generally very low with regards to the first tertile, since, in both cases, the share of patches which show null values is over $90 \%$ of the total area. With regards to the second and third tertiles, the share of the area of null-value patches of protected areas is quite lower than in the case of the first tertile (around 20\%). This occurs in the case of unprotected areas as well, even though the share of the null-value area is more than double. 
The most outstanding policy recommendation aimed at increasing the eligibility of patches to be included in the regional GI is that the environmental protection regime related to habitats and species should be extended beyond the boundaries of the Natura 2000 sites (as, for instance, in the Bosa area in Section 3, mapped in Figure 2A), since conservation measures concerning Natura 2000 sites are already in force in these areas. Moreover, it has to be stressed that the total surface of unprotected areas is about fourfold the surface of protected areas, which confirms that planning and normative efforts should be concentrated on additional measures to identify and protect habitats and species, in order to increase the eligibility of patches to be included in the regional GI.

From this perspective, planning policies need to focus on the advancement of scientific knowledge related to areas not located within Natura 2000 sites but still characterized by the presence of habitats and species, in order to lobby for the enlargement of the Natura 2000 Network. This recommendation is supported, for instance, by Maiorano et al. [52] who advocate integrated management of Natura 2000 sites and of their surrounding areas because control over human activities in the neighboring areas improves the effectiveness of conservation actions within Natura 2000 sites. Therefore, regional planning efforts should focus both on scientific knowledge improvement concerning habitats and species, and on a lobbying activity which should involve the national government and the European Union, in order to increase the share of the regional land included in the Natura 2000 Network. In the literature, several tools have been developed in order to help planners and decision-makers to identify areas with significant biodiversity value [53]. A first typology, including tools such as Marxan [54] and C-Plan [55], accounts for the location and configuration of these areas. A second typology accounts for the relationship between biodiversity and the environment: these tools identify potential conservation areas with regards to the relationship between species distribution and environmental conditions [56]. A third typology, including InVEST [57] and GLOBIO [58], includes threats distribution.

The taxonomy of VAL_L shows different features as well. The area of the null value patches belonging to the third tertile is very low both in case of protected and unprotected areas, and, consistently, the area of the non-null value patches is high. The area of the non-null patches within the second tertile goes down, dramatically and consistently in both cases, even though the share of the area of null-value patches located in protected areas is higher than in the case of unprotected areas, which implies that the number of landscape assets located in unprotected areas is relatively higher than in the case of protected areas. Finally, VAL_L is close to zero in protected and unprotected areas belonging to the first tertile.

Policy planning implications concerning VAL_L are quite straightforward. Planning measures with regards to protected and unprotected areas should aim to analytically and extensively identify the landscape assets related to historic and cultural resources (as, for instance, in the Giara area in Section 3, mapped in Figure 2B, whose prehistoric remains might not be fully explored), and to the environmental framework. This is a fine-tuning operation entailed by the co-planning procedure concerning the definition and the adoption of municipal masterplans, which involves the national Ministry of cultural goods and activities and of tourism, the Sardinian regional administration, and the local municipalities. Historic, cultural and environmental goods can acquire the status of protected landscape assets after the implementation of the procedural process established under the provisions of the Italian Code on cultural goods and landscape (Law enacted by decree no. 2004/42). Various authors [5,38] highlight the relationship between GI and landscape assets. For example, Benedict and McMahon [5] criticize how national conservation programs have dealt with the protection and conservation of parks and reserves over the last century. In fact, protected areas were usually conceived as isolated entities; however, in the last decades, conservation biologists have demonstrated that isolation hinders conservation objectives. GI have, therefore, been advocated as the tool to connect these protected areas. Moreover, the identification of a GI can benefit not only environmental resources, but also social and cultural resources, as exemplified by Orantes et al. [38] who develop a methodology to implement a GI plan, based on the integration of social and cultural assets, in the case of Yesan, Korea. 
Finally, with reference to VAL_R, the share of the area of the null-value patches of protected and unprotected areas is higher than $70 \%$, irrespective of the tertile. The values related to protected areas within the second tertile are comparatively higher than the other case, whereas the opposite holds for the third tertile. A possible explanation, in the case of the second tertile, is that the outcome is likely to depend on the different environmental protection regimes in force, which make unprotected areas comparatively more accessible, and, for this reason, it is easier for tourists to post images concerning unprotected areas. However, the low accessibility effect can be more than compensated by the attractive features of protected areas within the third tertile, characterized by the highest environmental and landscape quality, which might explain why the number of images posted from these areas is comparatively larger.

A recent study [13] gives evidence that recreational attractiveness is very important as a driving force for the inclusion of patches in the Sardinian regional GI. In other words, the contribution of recreational attractiveness, measured through the number of posted images, is particularly significant with regards to leisure-related ES. However, the results of this study show that there is no evidence of a relationship between attractiveness and regimes of environmental protection. As a consequence, the eligibility of patches to be included in the regional GI is not clearly influenced by the areas' location, whether they were inside or outside protected areas.

Various studies [59-61] demonstrate that recreational attractiveness, conceived as recreation demand, is influenced by different site attributes, such as accessibility and presence of accommodation options. Heagney et al. [60], by exploring the influence of several site attributes on recreational demand in relation to 728 protected areas, located in the state of New South Wales, Australia, indicate that accessibility represents a value added that needs to be assessed in terms of recreational potential from the early stages of the site establishment-related planning process, although the establishment of any protected area entails a base level of recreational demand due to visitors' expectations of the existing site values.

\section{Conclusions}

This study evaluates the suitability of areas, inside and outside protected areas, to be included in a regional GI, identified through four values (conservation value, natural value, recreational value and landscape value). In particular, this methodology attempts to operationalize multifunctionality, one of the two key concepts that characterize GI, and to derive planning recommendations that, by increasing the values of each factor, and hence the total value, focus on the multiple functions implied by the factors in order to increase the eligibility of null patches to belong to the regional GI.

Other studies analyze and identify GI only in relation to one of the concepts. For example, in relation to the multifunctionality concept, Vallecillo et al. [62] define a methodology to identify potential areas for the spatial planning of GI and ecosystem restoration, using methods of spatial conservation prioritization and comparing three alternative scenarios. To the contrary, other scholars, such as de la Fuente et al. [63] and Pelorosso et al. [64], study GI only in relation to the connectivity concept. From this perspective, studying GI by considering only one of the two key concepts above does not invalidate the results.

The methodology developed by Lai and Leone [20] which was applied here should be conceived as a tool to assist policy makers and planners to identify potential areas that can be included in a regional GI. In fact, GI should be included within spatial and landscape planning, such as in the case of the Lombardy region, where the implementation of a regional GI represents a key component of the regional landscape plan [19]. Moreover, although the proposed methodology builds upon Arcidiacono et al.'s previous work [19], it has some innovative aspects, such as including the conservation value and, by doing so, implementing the concept of biodiversity conservation into the definition of a GI, as suggested by the European Commission in the Biodiversity Strategy. In fact, target no. 2 states that by 2020 at least $15 \%$ of the degraded ecosystem has to be restored through the establishment of GI. 
The first advantage of the proposed methodology is that it shows a certain degree of flexibility which can be easily used to analyze other Italian and European regional contexts, since the Natura 2000 Network spreads all over the European Union countries, under the provisions of the Habitats and Birds Directives, and Natura 2000 sites are identified and described in the Standard data forms, as stated by the Decision no. 2011/484/EU of 11 July 2011. The other protection regimes that the study takes into account are easily comparable to the European Union's regimes, even though the national contexts show differentiated institutional frameworks. Moreover, the flexibility of the methodology makes it possible to add new values for obtaining the total value, in relation to the normative, social and economic characteristics of other national contexts. A very interesting aspect with regards to comparative studies concerning European countries is the definition of recommendations related to planning policies, with reference to both analogies and differences, and to public institutions and bodies involved in the implementation of these policies. Second, the proposed methodology uses data, such as land cover/land uses maps or data from social media, that are readily available.

On the other hand, the study shows some limitations that should be addressed in future research. First, the issue of leisure and tourist attractiveness needs further specific insights and represents a promising field for further study, since the recreational value is rather volatile and its measures are questionable. Integrating the judgments of non-experts, such as citizens and local communities, could be a possible future research direction in order to obtain social-perceptual information on cultural and recreational services, by building upon works such as Rall et al. [65] who study the added value generated by public participation on GI, in particular in relation to cultural and recreational services. Second, there is room for improvement in the way the total value is here calculated. As in the first case, non-expert judgments could be embedded in the definition of the total value, which, in the present version, is calculated as a sum of the four values. Future research could consider calculating the total value as a weighted sum, where the specific weights of each single value are defined through a combination of judgments from both experts and non-experts. It is expected that, by including non-expert opinions such as those from local communities, weights would be location-specific and time-specific.

Author Contributions: S.L., F.L., and C.Z. collaboratively designed the research and jointly wrote Sections 1 and 5. Individual contributions are as follows: F.L. wrote Section 2; S.L. wrote Section 3; and C.Z. wrote Section 4.

Funding: This study was supported by the Research Program “Natura 2000: Assessment of management plans and definition of ecological corridors as a complex network", funded by the Autonomous Region of Sardinia for the period 2015-2018, under the Call for "Projects related to fundamental or basic research" of the year 2013, implemented at the Department of Civil and Environmental Engineering and Architecture (DICAAR) of the University of Cagliari, Italy.

Conflicts of Interest: The authors declare no conflict of interest. The founding sponsors had no role in the design of the study; in the collection, analyses, or interpretation of data; in the writing of the manuscript, and in the decision to publish the results.

\section{References}

1. Benedict, M.; McMahon, E. Green Infrastructure: Linking Landscapes and Communities; Sprawl Watch Clearinghouse Monograph Series; Island Press: Washington, DC, USA, 2006; Available online: http: / / www.sprawlwatch.org/greeninfrastructure.pdf (accessed on 13 September 2018).

2. Landscape Institute. Green Infrastructure Connected and Multifunctional Landscapes: Position Statement; Landscape Institute: London, UK, 2009.

3. Liquete, C.; Kleeschulte, S.; Dige, G.; Maes, J.; Grizzetti, B.; Olah, B.; Zulian, G. Mapping green infrastructure based on ecosystem services, and ecological networks: A pan-European case study. Environ. Sci. Policy 2015, 54, 268-280. [CrossRef]

4. Lennon, M. Green infrastructure and planning policy: A critical assessment. Local Environ. 2015, 20, 957-980. [CrossRef]

5. Benedict, M.; McMahon, E. Green Infrastructure: Smart Conservation for the 21st Century; Sprawl Watch Clearinghouse: Washington, DC, USA, 2002. 
6. Lafortezza, R.; Davies, C.; Sanesi, G.; Konijnendijk, C.C. Green Infrastructure as a tool to support spatial planning in European urban regions. iForest 2013, 6, 102-108. [CrossRef]

7. Hansen, R.; Pauleit, S. From multifunctionality to multiple ecosystem services? A conceptual framework for multifunctionality in Green Infrastructure planning for urban areas. AMBIO 2014, 43, 516-529. [CrossRef] [PubMed]

8. Wang, J.; Banzhaf, E. Towards a better understanding of green infrastructure: A critical review. Ecol. Indic. 2018, 85, 758-772. [CrossRef]

9. Millennium Ecosystem Assessment. Ecosystems and Human Well-Being: A Framework for Assessment; Island Press: Washington, DC, USA, 2003.

10. CICES Version 5.1 Now Available. Available online: https:/ / cices.eu/ (accessed on 19 September 2018).

11. Landers, D.; Nahlik, A. Final Ecosystem Goods and Services Classification System (FEGS-CS); U.S. Environmental Protection Agency: Washington, DC, USA, 2013.

12. Taylor-Lovell, S.; Taylor, J.R. Supplying urban ecosystem services through multifunctional green infrastructure in the United States. Landsc. Ecol. 2013, 28, 1447-1463. [CrossRef]

13. Cannas, I.; Lai, S.; Leone, F.; Zoppi, C. Green infrastructure and ecological corridors: A regional study concerning Sardinia. Sustainability 2018, 10, 1265. [CrossRef]

14. Hansen, A.J.; DeFries, R. Ecological mechanisms linking protected areas to surrounding lands. Ecol. Appl. 2007, 17, 974-988. [CrossRef] [PubMed]

15. Gaston, K.J.; Charman, K.; Jackson, S.F.; Armsworth, P.R.; Bonn, A.; Briers, R.A.; Callaghan, C.S.Q.; Catchpole, R.; Hopkins, J.; Kunin, W.E.; et al. The ecological effectiveness of protected areas: The United Kingdom. Biol. Conserv. 2006, 132, 76-87. [CrossRef]

16. Ruiz Benito, P.; Cuevas, J.A.; Bravo de la Parra, R.; Prieto, F.; García del Barrio, J.M.; Zavala, M.A. Land use change in a Mediterranean metropolitan region and its periphery: Assessment of conservation policies through CORINE Land Cover data and Markov models. Forest Syst. 2010, 19, 315-328. [CrossRef]

17. Wickham, J.D.; Riitters, K.H.; Wade, T.G.; Vogt, P. A national assessment of green infrastructure and change for the conterminous united states using morphological image processing. Landsc. Urban Plan. 2010, 94, 186-195. [CrossRef]

18. Spanò, M.; Gentile, F.; Davies, C.; Lafortezza, R. The DPSIR framework in support of green infrastructure planning: A case study in Southern Italy. Land Use Policy 2017, 61, 242-250. [CrossRef]

19. Arcidiacono, A.; Ronchi, S.; Salata, S. Managing multiple ecosystem services for landscape conservation: A green infrastructure in Lombardy Region. Procedia Eng. 2016, 161, 2297-2303. [CrossRef]

20. Lai, S.; Leone, F. A methodological approach to identify a multifunctional green infrastructure at the regional scale. A case study from Sardinia, Italy. Urban. Inf. 2017, 272, 836-840.

21. Salomaa, A.; Paloniemi, R.; Kotiaho, J.S.; Kettunen, M.; Apostolopoulou, E.; Cent, J. Can green infrastructure help to conserve biodiversity? Environ. Plan. C 2017, 35, 265-288. [CrossRef]

22. Weber, T.; Sloan, A.; Wolf, J. Maryland's Green Infrastructure Assessment: Development of a comprehensive approach to land conservation. Landsc. Urban Plan. 2006, 77, 94-110. [CrossRef]

23. Sharma, R.; Nehren, U.; Rahman, S.A.; Meyer, M.; Rimal, B.; Seta, G.A.; Baral, B. Modeling land use and land cover changes and their effects on biodiversity in Central Kalimantan, Indonesia. Land 2018, 7, 57. [CrossRef]

24. Polasky, S.; Nelson, E.; Pennington, D.; Johnson, K.A. The impact of land-use change on ecosystem services, biodiversity and returns to landowners: A case study in the state of Minnesota. Environ. Resour. Econ. 2011, 48, 219-242. [CrossRef]

25. Yang, S.; Zhao, W.; Liu, Y.; Wang, S.; Wang, J.; Zhai, R. Influence of land use change on the ecosystem service trade-offs in the ecological restoration area: Dynamics and scenarios in the Yanhe watershed, China. Sci. Total Environ. 2018, 644, 556-566. [CrossRef] [PubMed]

26. Serkan, G.; Rehber, E. A travel cost study to estimate recreational value for a bird refuge at Lake Manyas, Turkey. J. Environ. Manag. 2008, 88, 1350-1360. [CrossRef]

27. Martín-López, B.; Gómez-Baggethun, E.; Lomas, P.L.; Montes, C. Effects of spatial and temporal scales on cultural services valuation. J. Environ. Manag. 2009, 90, 1050-1059. [CrossRef] [PubMed]

28. Lankia, T.; Kopperoinen, L.; Pouta, E.; Neuvonen, M. Valuing recreational ecosystem service flow in Finland. J. Outdoor Recreat. Tour. 2015, 10, 14-28. [CrossRef]

29. Mayer, M.; Woltering, M. Assessing and valuing the recreational ecosystem services of Germany's national parks using travel cost models. Ecosyst. Serv. 2018, 31, 371-386. [CrossRef] 
30. Kenter, J.O. Deliberative and non-monetary valuation: A review of methods. In Handbook of Ecosystem Services; Potschin, M., Haines-Young, R., Fish, R., Turner, R.K., Eds.; Routledge: London, UK, 2016; pp. 271-288. ISBN 9781317687047.

31. Kelemen, E.; García-Llorente, M.; Pataki, G.; Martín-López, B.; Gómez-Baggethun, E. Non-monetary techniques for the valuation of ecosystem service. In OpenNESS Reference Book EC FP7 Grant Agreement No. 308428; Potschin, M., Jax, K., Eds.; EU Publication Office: Luxembourg, 2014; Available online: http:/ / www.openness-project.eu/sites/default/files/SP-Non-monetary-valuation.pdf (accessed on 19 September 2018).

32. Eagles, P.; McLean, D.; Stabler, M. Estimating the tourism volume and value in protected areas in Canada and the USA. George Wright Forum 2000, 17, 62-76.

33. Wood, S.A.; Guerry, A.D.; Silver, J.M.; Lacayo, M. Using social media to quantify nature-based tourism and recreation. Sci. Rep. 2013, 3, 2976. [CrossRef] [PubMed]

34. Sonter, L.J.; Watson, K.B.; Wood, S.A.; Ricketts, T.H. Spatial and temporal dynamics and value of nature-based recreation, estimated via social media. PLoS ONE 2016, 11, e0162372. [CrossRef] [PubMed]

35. Hausmann, A.; Toivonen, T.; Slotow, R.; Tenkanen, H.; Moilanen, A.; Heikinheimo, V.; Di Minin, E. Social media data can be used to understand tourists' preferences for nature-based experiences in protected areas. Conserv. Lett. 2018, 11, e12343. [CrossRef]

36. Cunha, J.; Elliott, M.; Ramos, S. Linking modelling and empirical data to assess recreation services provided by coastal habitats: The case of NW Portugal. Ocean Coast. Manag. 2018, 162, 60-70. [CrossRef]

37. Zoppi, C.; Lai, S. Assessment of the Regional Landscape Plan of Sardinia (Italy): A participatoryaction-research case study type. Land Use Policy 2010, 27, 690-705. [CrossRef]

38. Orantes, M.J.C.; Kim, J.; Kim, J. Socio-cultural asset integration for a green infrastructure network plan in Yesan County, Korea. Sustainability 2017, 9, 191. [CrossRef]

39. CRITERIA; TEMI. Monitoraggio dello Stato di Conservazione degli Habitat e delle Specie di Importanza Comunitaria Presenti nei Siti della Rete Natura 2000 in Sardegna. Definizione della Rete di Monitoraggio. Volume 2: Piano di Monitoraggio degli Habitat e delle Specie Vegetali; MIMEO: New York, NY, USA, 2014.

40. CRITERIA; TEMI. Monitoraggio dello Stato di Conservazione degli Habitat e delle Specie di Importanza Comunitaria Presenti nei Siti della Rete Natura 2000 in Sardegna. Elaborazione Rapporto di Sintesi sullo Stato di Conservazione di Habitat e Specie (Linea 4, 4.C.1); MIMEO: New York, NY, USA, 2014.

41. Burkhard, B.; Kroll, F.; Müller, F.; Windhorst, W. Landscapes' capacities to provide ecosystem services-A concept for land-cover based assessments. Landsc. Online 2009, 15, 1-22. [CrossRef]

42. Burkhard, B.; Kroll, F.; Nedkov, S.; Müller, F. Mapping ecosystem service supply, demand and budgets. Ecol. Indic. 2012, 21, 17-29. [CrossRef]

43. De Groot, R.S.; Alkemade, R.; Braat, L.; Hein, L.; Willemen, L. Challenges in integrating the concept of ecosystem services and values in landscape planning, management and decision making. Ecol. Complex. 2010, 3, 260-272. [CrossRef]

44. De Montis, A.; Caschili, S. Nuraghes and landscape planning: Coupling viewshed with complex network analysis. Landsc. Urban Plan. 2012, 105, 315-324. [CrossRef]

45. Blake, E. Sardinia's nuraghi: Four millennia of becoming. World Archaeol. 1998, 30, 50-71. [CrossRef]

46. Minchilli, M.; Tedeschi, L.F. The geographical distribution of nuraghi in north-western Sardinia: Analysis and evaluation of the influence of anthropic and natural factors. In Computational Science and Its Applications-ICCSA 2017, Proceedings of the 17th International Conference on Computational Science and Its Applications (ICCSA 2017), Trieste, Italy, 3-6 July 2017; Lecture Notes in Computer Sciences Series; Springer: Cham, Switzerland, 2017; Volume 10408, pp. 701-712. ISBN 978-3-319-62403-7.

47. Rendeli, M. Sardinia. In Etruscology; De Naso, A., Ed.; Walter de Gruyter GmbH: Berlin, Germany, 2017; pp. 1669-1678.

48. Lai, S.; Leone, F.; Zoppi, C. Land cover changes and environmental protection: A study based on transition matrices concerning Sardinia (Italy). Land Use Policy 2017, 67, 126-150. [CrossRef]

49. Lai, S.; Leone, F.; Zoppi, C. Anthropization processes and protection of the environment: An assessment of land cover changes in Sardinia, Italy. Sustainability 2017, 9, 2174. [CrossRef]

50. He, J.; Huanga, J.; Li, C. The evaluation for the impact of land use change on habitat quality: A joint contribution of cellular automata scenario simulation and habitat quality assessment model. Ecol. Model. 2017, 366, 58-67. [CrossRef] 
51. Sallustio, L.; De Toni, A.; Strollo, A.; Di Febbraro, M.; Gissi, E.; Casella, L.; Geneletti, D.; Munafò, M.; Vizzarri, M.; Marchetti, M. Assessing habitat quality in relation to the spatial distribution of protected areas in Italy. J. Environ. Manag. 2017, 201, 129-137. [CrossRef] [PubMed]

52. Maiorano, L.; Falcucci, A.; Garton, E.O.; Boitani, L. Contribution of the Natura 2000 network to biodiversity conservation in Italy. Conserv. Biol. 2007, 21, 1433-1444. [CrossRef] [PubMed]

53. Terrado, M.; Sabater, S.; Chaplin-Kramer, B.; Mandle, L.; Ziv, G.; Acuña, V. Model development for the assessment of terrestrial and aquatic habitat quality in conservation planning. Sci. Total Environ. 2016, 540, 63-70. [CrossRef] [PubMed]

54. Ball, I.R.; Possingham, H.P.; Watts, M. Marxan and relatives: Software for spatial conservation prioritization. In Spatial Conservation Prioritization: Quantitative Methods and Computational Tools; Moilanen, A., Wilson, K.A., Possingham, H.P., Eds.; Oxford University Press: New York, NY, USA, 2009; pp. 185-195. ISBN 9780199547777.

55. Pressey, R.L.; Watts, M.E.; Barrett, T.W.; Ridges, M.J. The C-Plan conservation planning system: Origins, applications, and possible futures. In Spatial Conservation Prioritization: Quantitative Methods and Computational Tools; Moilanen, A., Wilson, K.A., Possingham, H.P., Eds.; Oxford University Press: New York, NY, USA, 2009; pp. 211-234. ISBN 9780199547777.

56. Kuemmerlen, M.; Schmalz, B.; Guse, B.; Cai, Q.; Fohrer, N.; Jähnig, S.C. Integrating catchment properties in small scale species distribution models of stream macroinvertebrates. Ecol. Model. 2014, 277, 77-86. [CrossRef]

57. Sharp, R.; Tallis, H.T.; Ricketts, T.; Guerry, A.D.; Wood, S.A.; Chaplin-Kramer, R.; Nelson, E.; Ennaanay, D.; Wolny, S.; Olwero, N.; et al. InVEST 3.5.0 User's Guide; The Natural Capital Project; Stanford University: Stanford, CA, USA; University of Minnesota: Minneapolis, MN, USA; The Nature Conservancy: Arlington, VA, USA; World Wildlife Fund: Morges, Switzerland, 2018.

58. Alkemade, R.; van Oorschot, M.; Miles, L.; Nellemann, C.; Bakkenes, M.; ten Brink, B. GLOBIO3: A framework to investigate options for reducing global terrestrial biodiversity loss. Ecosystems 2009, 12, 374-390. [CrossRef]

59. Amoako-Tuffour, J.; Martinez-Espineira, R. Leisure and the net opportunity cost of travel time in recreation demand analysis: An application to Gros Morne national park. J. Appl. Econ. 2012, 15, 25-49. [CrossRef]

60. Heagney, E.C.; Rose, J.M.; Ardeshiri, A.; Kovac, M. Optimising recreation services from protected areas-Understanding the role of natural values, built infrastructure and contextual factors. Ecosyst. Serv. 2018, 31, 358-370. [CrossRef]

61. Font, A.R. Mass tourism and the demand for protected natural areas: A travel cost approach. J. Environ. Econ. Manag. 2000, 39, 97-116. [CrossRef]

62. Vallecillo, S.; Polce, C.; Barbosa, A.; Castillo, C.P.; Vandecasteele, I.; Rusch, G.M.; Maes, J. Spatial alternatives for Green Infrastructure planning across the EU: An ecosystem service perspective. Landsc. Urban Plan. 2018, 174, 41-54. [CrossRef]

63. De la Fuente, B.; Mateo-Sánchez, M.; Rodríguez, G.; Gastón, A.; de Ayala, R.P.; Colomina-Pérez, D.; Melero, M.; Saura, S. Natura 2000 sites, public forests and riparian corridors: The connectivity backbone of forest green infrastructure. Land Use Policy 2018, 75, 429-441. [CrossRef]

64. Pelorosso, R.; Gobattoni, F.; Geri, F.; Leone, A. PANDORA 3.0 plugin: A new biodiversity ecosystem service assessment tool for urban green infrastructure connectivity planning. Ecosyst. Serv. 2017, 26, 476-482. [CrossRef]

65. Rall, E.; Hansen, R.; Pauleit, S. The added value of public participation GIS (PPGIS) for urban green infrastructure planning. Urban For. Urban Green. 2018. [CrossRef]

(C) 2018 by the authors. Licensee MDPI, Basel, Switzerland. This article is an open access article distributed under the terms and conditions of the Creative Commons Attribution (CC BY) license (http:/ / creativecommons.org/licenses/by/4.0/). 